УДК 621.396.674.3

\title{
ХАРАКТЕРИСТИКИ СОГЛАСОВАНИЯ И ИЗЛУЧЕНИЯ ФАР НА ОСНОВЕ КВАЗИ-ЯГИ ПЕЧАТНЫХ АНТЕНН ПРИ НАЛИЧИИ ДОПОЛНИТЕЛЬНОГО ЭКРАНА
}

\author{
ВИДАЛКО О. Е., ДУБРОВКА Ф. Ф. \\ Национальный технический университет Украинь \\ «Киевский политехнический институт», \\ Украина, Киев, 03056, пр-т Победы 37
}

\begin{abstract}
Аннотация. Представлены результаты численного исследования и оптимизации характеристик согласования и излучения отдельной печатной квази-Яги антенны и плоской фазированной антенной решетки (ФАР) размером 11×11 элементов, построенной на основе таких излучателей. Исследование выполнено методом конечных разностей во временной области. В расчетах учтено наличие дополнительного металлического экрана за излучающим полотном и питание каждого элемента решетки через коаксиально-микрополосковый переход, что максимально приблизило модель антенной решетки к реальной конструкции ФАР и ее работе в реальных условиях. Исследованы уровни электромагнитной связи между соседними элементами решетки, показаны изменения рабочих характеристик элементов в ее составе при синфазном возбуждении и в режиме сканирования. Установлено, что возможный сектор сканирования такой экранированной ФАР лежит в пределах $\pm 45^{\circ}$ при коэффициенте отражения любого ее элемента менее -10 дБ в полосе частот не менее $10 \%$, а центрального элемента решетки - в полосе рабочих частот более $30 \%$ при сканировании в $E$-плоскости и не менее $17 \%$ — при сканировании в $H$-плоскости
\end{abstract}

Ключевые слова: печатная антенна; микрополосковый излучатель; печатная квази-Яги антенна; фазированная антенная решетка; взаимная электромагнитная связь; сканирование главным лепестком

\section{ВВЕДЕНИЕ}

ФАР на основе микрополосковых антенн представляют особый интерес для использования в современной радиолокации. Их основные преимущества над остальными типами ФАР — компактность, малый вес, легкость компоновки с интегральными микросхемами и сравнительно низкая стоимость производства. Среди антенн такого типа перспективными для нужд радиолокации являются микрополосковые антенны бегущей волны, которые, в отличие от резонансных, имеют широкую полосу рабочих частот.

К микрополосковым антеннам бегущей волны возможно отнести печатную квази-Яги антенну, обладающую широкой полосой рабочих частот и сравнительно небольшой взаимной связью в составе ФАР [1-3]. Благодаря этим качествам квази-Яги антенны привлекли внимание разработчиков ФАР [2-5].

В данной работе представлены результаты численного исследования и оптимизации характеристик согласования и излучения отдельной печатной квази-Яги антенны при наличии экрана и ФАР на основе таких излучателей с учетом взаимной связи между элементами. Исследованы возможности широкоугольного сканирования таких ФАР. Исследуемая модель ФАР максимально приближена к реальной конструкции ФАР за счет наличия дополни- 